\title{
DETERMination OF THE MEASUREMENT DeViation
}

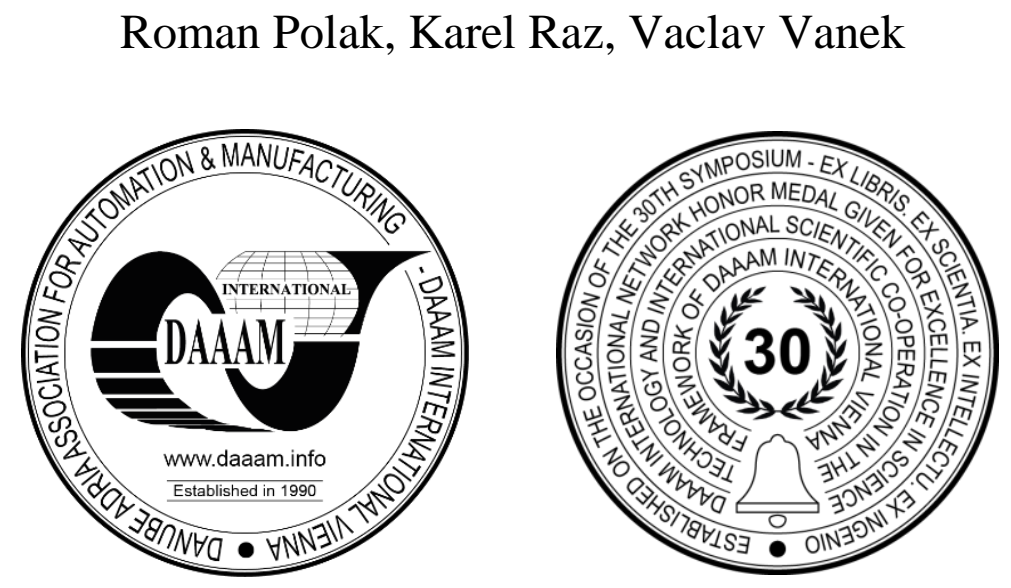

This Publication has to be referred as: Polak, R[oman]; Raz, K[arel] \& Vanek, V[aclav] (2019). Determination of the Measurement Deviation, Proceedings of the 30th DAAAM International Symposium, pp.0539-0544, B. Katalinic (Ed.), Published by DAAAM International, ISBN 978-3-902734-22-8, ISSN 1726-9679, Vienna, Austria DOI: $10.2507 / 30$ th.daaam.proceedings.073

\begin{abstract}
This article deals with the determination of deviations measurement in mechanical testing laboratories. The main problem is in calculation of these measurement deviations in acceptable time and creation of the record of this process. Most measurements contain multiple deviations, which are affecting the overall result. The process of application developing for automatic calculation measurement errors with calculating details is described in this article. The application is focused on usage of various types of measurements (tensile tests, compression and impact tests, hardness and cyclic testing, etc.). It should be performed independently on the measuring machine. This solution is compared with other potential methods of combined measurement deviations calculating.
\end{abstract}

Keywords: measurement deviation; automation software; mechanical testing;

\section{Introduction}

Measurement deviations occur on all measuring instruments and equipment used in the measurement process. Most types of measurements use more than one device to determine the result. For this reason, the measurement result affects every device used in the measurement process. The resulting values are displayed on the devices but without corresponding measurement deviations. These deviations shall be calculated on the basis of the measured values and results of equipment calibration. [1] The detailed procedure for each measurement is described below. These procedures and methods of verification are newly required as one of the conditions for accreditation of measuring laboratories. This condition has to describe the calculation with manual verification, but in practice this method is very time consuming. For these reasons, an automated process has been developed that covers all steps from the measuring instrument, through the calculation of measurement variations to determine the resulting value. The main reasons for this software development were multiple factors. In particular, the fulfilment of laboratory accreditation conditions and the acceleration of the deviation calculation process. 70\% of machine errors are caused by temperature conditions of the measuring machine and its surroundings. [9] The ILAC Mutual Recognition Arrangement (ILAC MRA) provides significant technical underpinning to the calibration, testing, medical testing and inspection results and provision of proficiency testing programs of the accredited conformity assessment bodies that in turn delivers confidence in the acceptance of results. In this way the ILAC MRA promotes international trade and the free-trade goal of "accredited once, accepted everywhere" can be realized. [6]

There are many kinds of mechanical tests. The procedure of the measurement deviation described above may be used for all these tests. The laboratory used for this process has measuring devices and instruments for measuring: 
- Tensile test

- Compression test

- Impact test

- Hardness and cyclic tests

Other types of measurements not listed here can be supplemented with the same calculation principle.
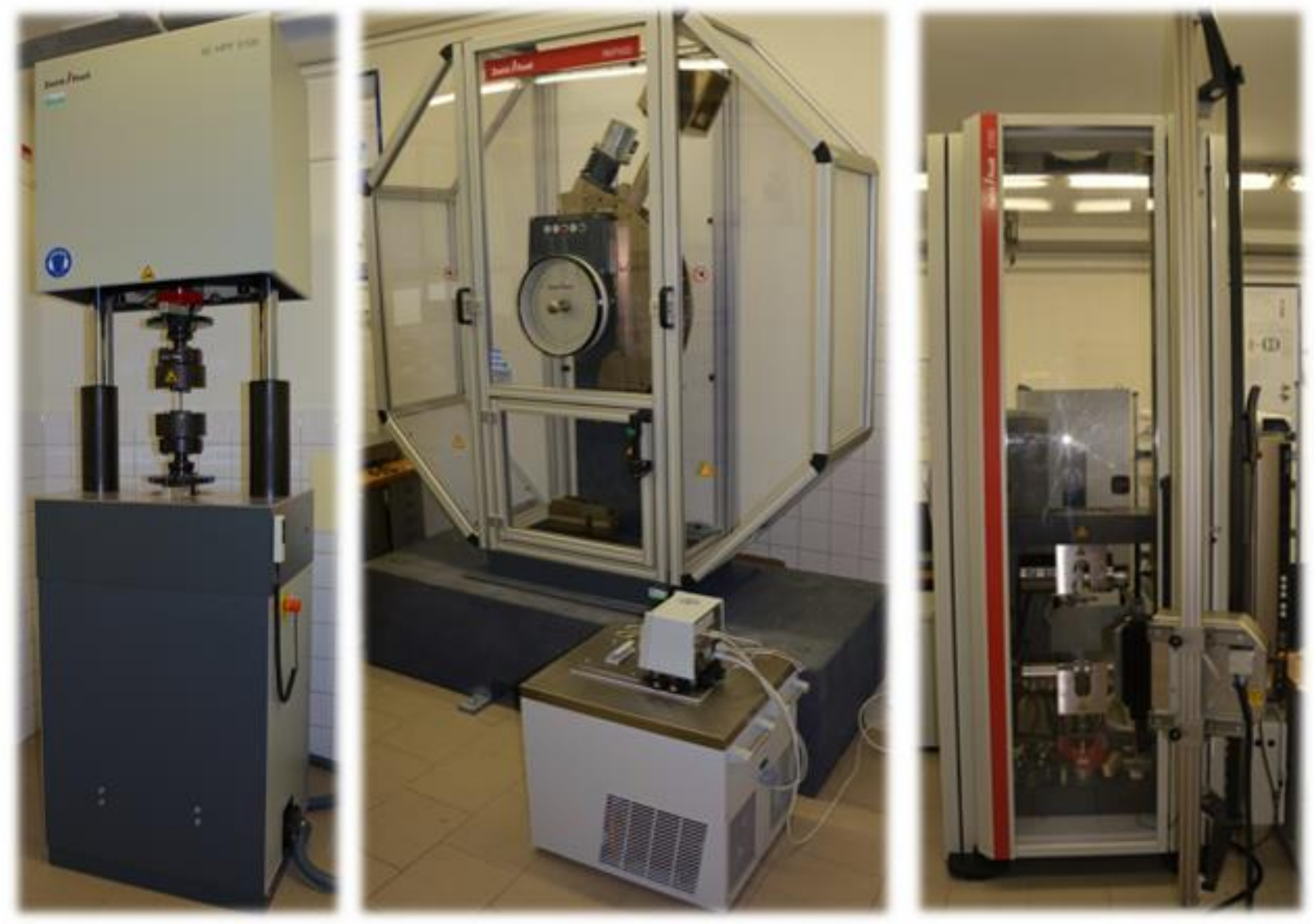

Fig. 1. Resonant pulsator (Zwick Roell HFP 50) - left, Hammer for impact test (Zwick Roell) - center, Universal tensile testing machine (Zwick Roell Z250 - right)

\section{Measuring process and verification}

A general description of the whole process is shown in Figure 2. The initial measurement is carried out in the same way as before. Depending on the type of measurement, measurements are performed in parallel or in series. Serial measurements are used for measurements where the result of one measurement affects the following measurements. The results of the individual measurements are the input of the software for determination of measurement deviation. After selecting the measurement type and entering the input values (output from the device), the software performs the calculation (example described in chapter 1.1 Tested sample). Machine information is managed in the software and stored in an external database. Each machine has its own valid calibration certificate. Alternatively, one machine can contain multiple calibration sheets for different machine measuring ranges. The software automatically selects the correct values from the calibration sheets and applies them to the measurement deviation calculations. The resulting measurement deviation is composed of individual deviations of the measuring devices and interpreted as a combined measurement deviation.

All information that this software works with is recorded in the log file. This file always contains information about the given measurement (identification number, type of measurement, input values, continuous results, values from calibration certificates, output values). This information can be further stored as history in an external database or exported to a single file. 


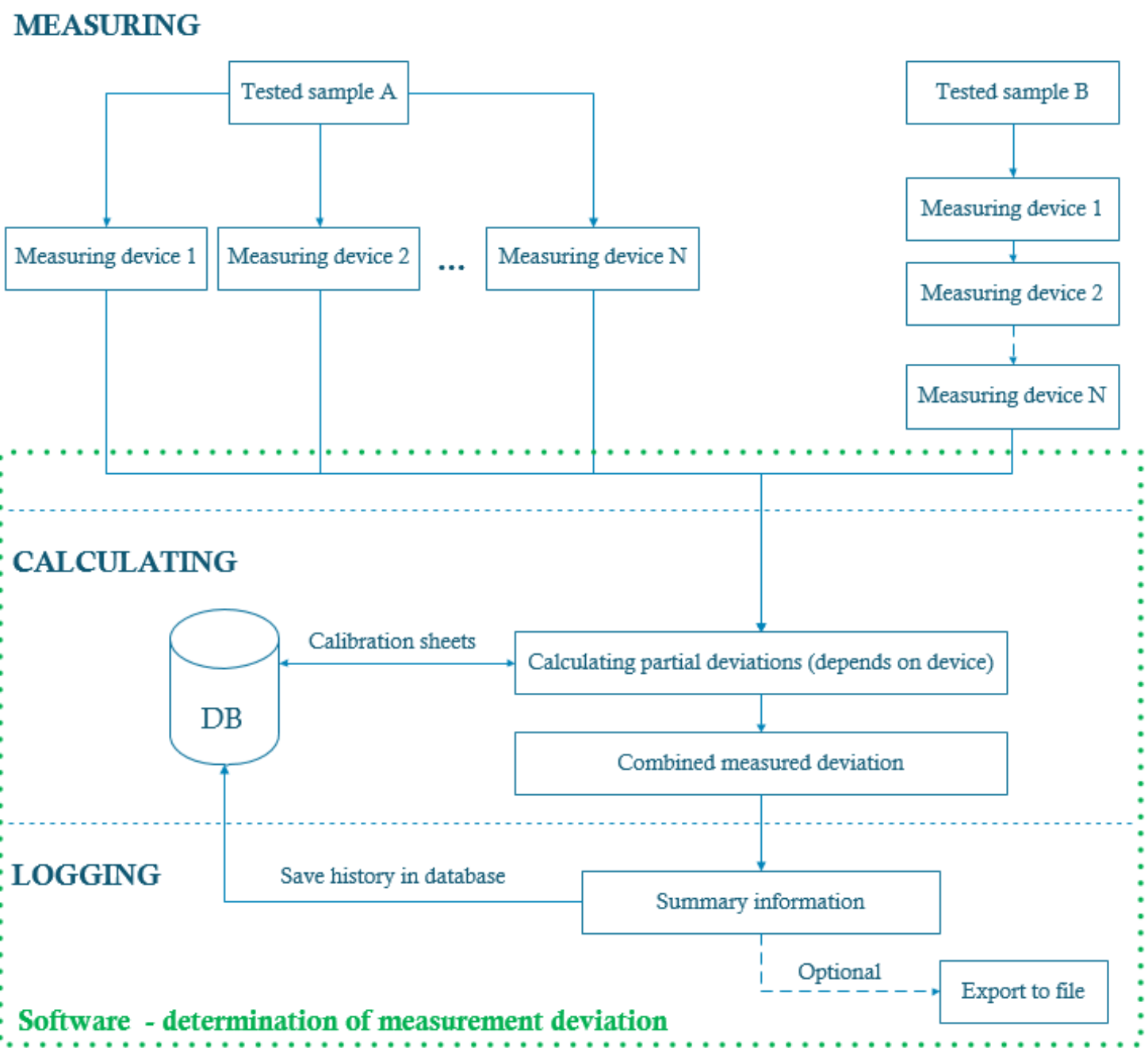

Fig. 2. Diagram of process

The stored information in the database can then be used to trace the results or in the case of a laboratory audit. An option is to export to an external file, which in many cases is required as additional information to the measurement. Microsoft SQL database was used in this process, but it is not essential for description of this principle. The database contains tables with values from machine calibration sheets. An example of a shredder calibration sheet is shown in Figure 3.

Kalibrační laboratoř č.: 2230 akreditovaná ČIA podle ČSN EN ISO/IEC 17025:2005

AKL ZÁLE Š́ K, s.r.o.

Kalibrační laborator̆

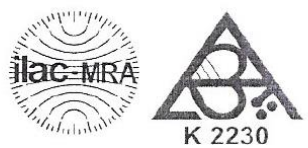

Korejská 27,616 00 Brno, tel.-fax.: 566666 514, mob.: 603512 082, e-mail: AKLZalesak@seznam.cz

\section{Kalibrační list č.: $\quad$ 2318-1-19}

Zjištěné výsledky měr̆ení:
\begin{tabular}{|c|ccc|c|c|c|c|c||}
\hline \multicolumn{9}{|c|}{ Rozsah: } \\
\hline Zatiženi & $(\mathrm{F}$ & $\pm \mathrm{U})[\mathrm{kN}]$ & $\mathrm{a}[\%]$ & $\mathrm{b}[\%]$ & $\mathrm{f}_{0}[\%]$ & $\mathrm{q}[\%]$ & $\mathrm{p}[\%]$ \\
\hline \hline 1 & 0,9990 & \pm & 0,0016 & 0,100 & 0,20 & 0,008 & 0,10 & 95 \\
\hline 2 & 1,9973 & \pm & 0,0070 & 0,050 & 0,15 & 0,008 & 0,13 & 95 \\
\hline 5 & 4,997 & \pm & 0,012 & 0,020 & 0,10 & 0,008 & 0,05 & 95 \\
\hline 10 & 9,995 & \pm & 0,016 & 0,010 & 0,07 & 0,008 & 0,05 & 95 \\
\hline 20 & 19,987 & \pm & 0,027 & 0,005 & 0,05 & 0,008 & 0,07 & 95 \\
\hline 50 & 49,95 & \pm & 0,12 & 0,002 & 0,10 & 0,008 & 0,11 & 95 \\
\hline 100 & 99,91 & \pm & 0,16 & 0,001 & 0,07 & 0,008 & 0,09 & 95 \\
\hline 150 & 149,83 & \pm & 0,27 & 0,001 & 0,07 & 0,008 & 0,11 & 95 \\
\hline 200 & 199,80 & \pm & 0,46 & 0,001 & 0,10 & 0,008 & 0,10 & 95 \\
\hline 250 & 249,67 & \pm & 0.71 & 0,000 & 0,12 & 0,008 & 0,13 & 95 \\
\hline
\end{tabular}

\begin{tabular}{||c|ccc|c|c|c|c|c|c||}
\hline \multicolumn{1}{|c}{ Rozsah: } & TLAK & \multicolumn{7}{c|}{$0-250 \mathrm{kN}$} \\
\hline Zatiženi & $(\mathrm{F}$ & $\pm \mathrm{U})[\mathrm{kN}]$ & $\mathrm{a}[\%]$ & $\mathrm{b}[\%]$ & $\mathrm{f}_{0}[\%]$ & $\mathrm{a}[\%]$ & $\mathrm{p}[\%]$ \\
\hline \hline 1 & 1,0017 & \pm & 0,0071 & 0,100 & 0,30 & 0,012 & 0,17 & 95 \\
\hline 2 & 2,0020 & \pm & 0,0092 & 0,050 & 0,20 & 0,012 & $-0,10$ & 95 \\
\hline 5 & 5,008 & \pm & 0,012 & 0,020 & 0,10 & 0,012 & $-0,15$ & 95 \\
\hline 10 & 10,017 & \pm & 0,027 & 0,010 & 0,10 & 0,012 & $-0,17$ & 95 \\
\hline 20 & 20,037 & \pm & 0,070 & 0,005 & 0,15 & 0,012 & $-0,18$ & 95 \\
\hline 50 & 50,07 & \pm & 0,12 & 0,002 & 0,10 & 0,012 & $-0,15$ & 95 \\
\hline 100 & 100,10 & \pm & 0,46 & 0,001 & 0,20 & 0,012 & $-0,10$ & 95 \\
\hline 150 & 150,10 & \pm & 0,46 & 0,001 & 0,13 & 0,012 & $-0,07$ & 95 \\
\hline 200 & 200,10 & \pm & 0,47 & 0,001 & 0,10 & 0,012 & $-0,05$ & 95 \\
\hline 250 & 250,00 & \pm & 0,47 & 0,000 & 0,08 & 0,012 & 0,00 & 95 \\
\hline
\end{tabular}

Fig. 3. Example of calibrating sheet 


\subsection{Tested sample}

Test sample ID - 2 was selected from the measurement results below (see Table 1) for an exemplary measurement uncertainty workflow and for the validation with usage of the specialized software. Other samples are counted in the same way. The term uncertainty is considered here as a measurement deviation. [2], [3], [4]

\begin{tabular}{|c|c|c|c|c|c|c|}
\hline ID & Material & $\begin{array}{c}\mathbf{b}_{\mathbf{0}} \\
{[\mathbf{m m}]}\end{array}$ & $\begin{array}{c}\mathbf{t} \\
{[\mathbf{m m}]}\end{array}$ & $\begin{array}{c}\mathbf{R}_{\mathbf{m}} \\
{[\mathbf{M P a}]}\end{array}$ & $\begin{array}{c}\mathbf{R}_{\mathbf{p 0 , 2}} \\
{[\mathbf{M P a}]}\end{array}$ & $\begin{array}{c}\mathbf{A 5 0} \\
{[\%]}\end{array}$ \\
\hline 2 & ENAW 7005-22/01/2018 & 12.3 & 1.6 & 185 & 113 & 19.3 \\
\hline 3 & ENAW 7005 - 02/10/2018 & 12.3 & 1.75 & 199 & 127 & 13 \\
\hline 4 & ENAW 7020T6 - 31/07/2018 & 12.2 & 1.6 & 375 & 328 & 15 \\
\hline 5 & ENAW 7020T6-06/11/2018 & 12.15 & 1.55 & 377 & 330 & 11,6 \\
\hline 6 & ENAW 7005 & 12.6 & 1.8 & 243 & 213 & 9.3 \\
\hline
\end{tabular}

Table 1. Measurement results

Input parameters for the calculation of the uncertainty bounds are the average diameter of the test sample $\mathrm{t}[\mathrm{mm}]$ and the measured value $\mathrm{Rm}$ [MPa] (1). The output is a combined measurement uncertainty consisting of these two uncertainties.

$$
\begin{aligned}
& R=185 M P a ; t=1.6 \mathrm{~mm} \\
& S_{0}=\pi \cdot r^{2} ;\left(r=\frac{t}{2}\right) \\
& S_{0}=\pi \cdot 0,8^{2}=2,01 \\
& F_{m}=R \cdot S=185 \cdot 2.01=371.85 \mathrm{~N}
\end{aligned}
$$

The uncertainties of the measurement of the pressure limit and the diameter of the measured sample are inputs for the overall calculation (2). These values must be read from the calibration sheets (strength limit) and caliper (diameter of the test sample) for further calculation (3). Combined measurement uncertainty describes the formula below.

$$
u\left(R_{m}\right)=\sqrt{\left(u\left(F_{m}\right)\right)^{2}+\left(u\left(S_{0}\right)\right)^{2}}
$$

$\mathrm{U}(\mathrm{Fm})$ is the value from calibration sheet of tensile machine and $\mathrm{u}(\mathrm{S})$ is the value from calibration sheet of caliper. The uncertainty of measurement is subtracted, based on the specified value of $\mathrm{Fm}=371.85 \mathrm{~N}$. The uncertainty is taken for the next higher limit of the machine scale (specifically $1 \mathrm{kN}$ ). The standard uncertainty reading is $\mathrm{UFm}=0.0046$ for $\mathrm{F}=1 \mathrm{kN}$. For the overall uncertainty (4), it is necessary to obtain an expanded measurement uncertainty which is the product of the standard measurement uncertainty and the inverse of the coefficient $\mathrm{k}$, which corresponds to a coverage probability of approximately $95 \%$, which for normal distribution corresponds to the coefficient $\mathrm{k}=2$. [5], [7]

$$
u\left(F_{m}\right)=\frac{U_{F m} \cdot 100}{F \cdot k}=\frac{0.0046 \cdot 100}{2}=\mathbf{0 . 2 3} \%
$$

The expanded measurement uncertainty of the tensile machine is $0.23 \%$. For measuring the diameter of the test sample, a caliper was used, where the uncertainty of measurement for the interval $0-150 \mathrm{~mm}$ is set to $\mathrm{u}=0.03 \mathrm{~mm}$ according to the calibration certificate. The measured sample has a diameter of $1.6 \mathrm{~mm}$.

$$
u\left(S_{0}\right)=\frac{U_{S 0} \cdot 100}{t \cdot k}=\frac{0.03 \cdot 100}{1.6 \cdot 2}=0.9375 \%
$$


The expanded measurement uncertainty (6) with a caliper is $0.9375 \%$. All the necessary measurement uncertainties are now available to determine the resulting combined measurement uncertainty (7).

$$
\begin{aligned}
& u\left(R_{m}\right)=\sqrt{\left(u\left(F_{m}\right)\right)^{2}+\left(u\left(S_{0}\right)\right)^{2}}=\sqrt{0.23^{2}+0.9375^{2}} \doteq 0.9653 \% \\
& \frac{u\left(R_{m}\right) \cdot R \cdot k}{100}=3.57 \\
& \boldsymbol{R}_{\boldsymbol{m}}=\mathbf{1 8 5} \pm \mathbf{3 . 5 7} \mathbf{M P a}
\end{aligned}
$$

Tensile strength of $185 \mathrm{MPa}$ is measured with an uncertainty of $3.57 \mathrm{MPa}(9)$ at $95 \%$ confidence level $(\mathrm{k}=2)(8)$.

\subsection{Verification with software}

The input parameters are the same as in the previous case. Calculation software was developed for mentioned types of mechanical tests in the introduction chapter.

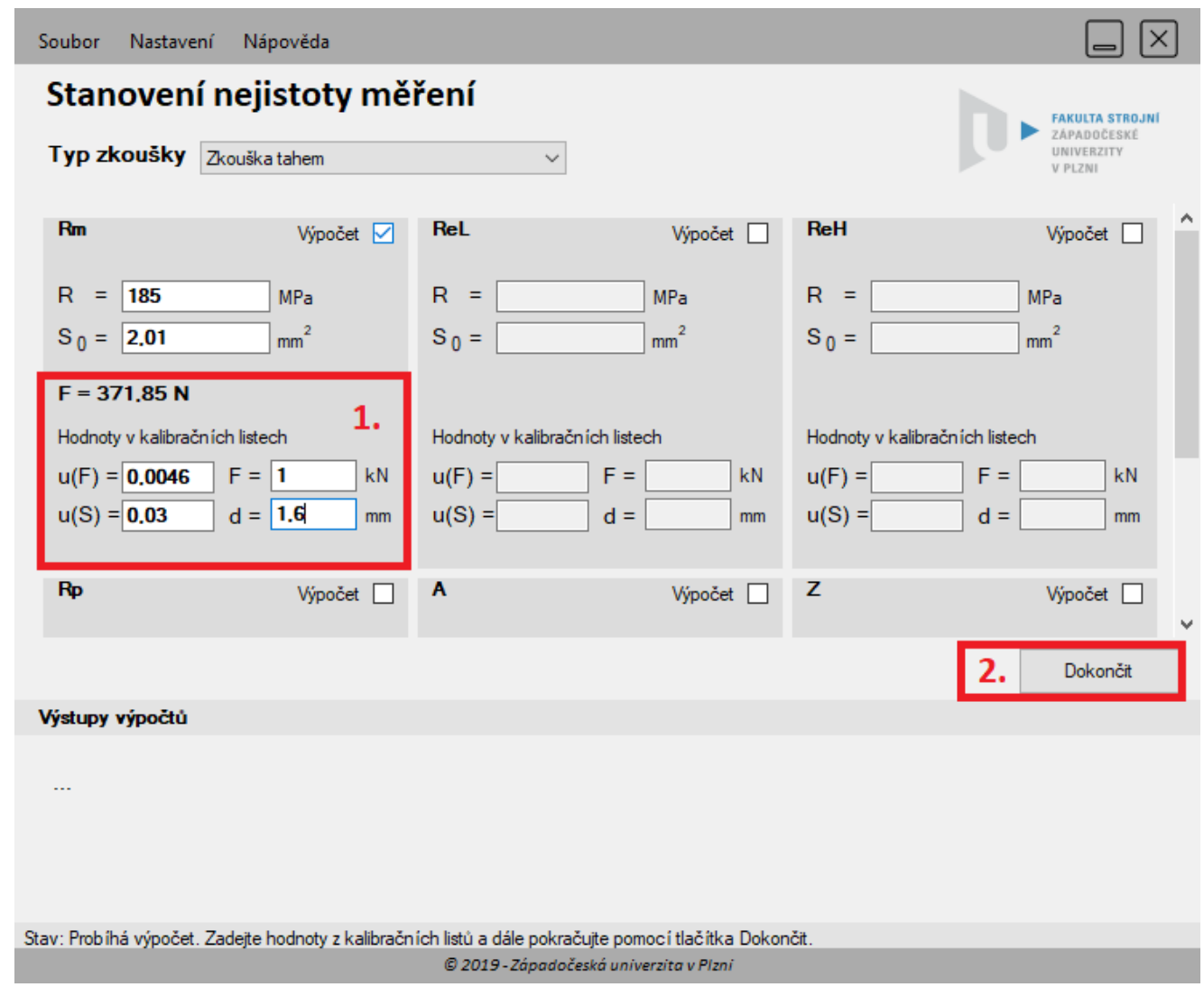

Fig. 4. User interface of verification sofware

By selecting the appropriate test, you can enter the input parameters and start the calculation. After entering the input parameters, the load $\mathrm{F}$ is calculated, with which the corresponding values can be read from the calibration sheets. The value $\mathrm{u}(\mathrm{S})$ is valid for the entire interval $0-150 \mathrm{~mm}$. After completing the values from the calibration sheets, it is possible to continue the calculation using the Finish button. Then the result is displayed in the section "Calculation outputs" and the whole calculation record is stored in the output log - see status bar. The output file contains the complete calculation record and is archived in the set location.

Computing software was written in C\# .NET language using Micosoft SQL database for calibration sheets management. Based on procedures and flowchart (both in this article), this software can be created using other development languages or software packages. [8] 


\section{Conclusion}

This paper describes the methodology of measurement deviation calculation including software solution. On the basis of this methodology it is possible to automate the individual phases and thus significantly speed up the method of calculation of measurement deviations. The original problem was in processing the measured values with their deviations in an acceptable time. Previous calculations were solved using formulas in Excel. This software solution greatly accelerated the overall calculation process and provides additional benefits (eg automatic reading of calibration sheets values, logging). The overall solution also minimizes user errors. Another acceleration and future improvement of the complete process would be automatic reading of values directly from the measuring instruments. This interface (if not part of the measuring machine) would have to send the measured values to a PC with this software. Then the process would continue in the same way and would be fully automated. Due to the variety of measuring instruments, it would be necessary to develop an interface between the devices and this software.

\section{Acknowledgments}

This paper has been prepared under project 'Research of additive technologies for future usage in mechanical engineering - RTI plus', CZ.02.1.01/0.0/0.0/18_069/0010040 of the Pre-application research for ITI of the Ministry of Education of the Czech Republic aimed at supporting research, development and education.

\section{References}

[1] Runje, B.; Horvatic Novak, A. \& Keran, Z. (2018). Impact of the Quality of Measurement Results on Conformity Assessment, Proceedings of the 29th DAAAM International Symposium, pp.0051-0055, B. Katalinic (Ed.), Published by DAAAM International, ISBN 978-3-902734-20-4, ISSN 1726-9679, Vienna, Austria DOI: 10.2507/29th.daaam.proceedings.007

[2] Kubatova, D. \& Melichar, M. (2018). Uncertainty of Surface Measurement, Proceedings of the 29th DAAAM International Symposium, pp.1239-1248, B. Katalinic (Ed.), Published by DAAAM International, ISBN 978-3902734-20-4, ISSN 1726-9679, Vienna, Austria DOI: 10.2507/29th.daaam.proceedings.179

[3] Adamczak, S.; Janecki, D.; Stepien, K. S. \& Wrzochal, M. (2017). An analysis Of Contemporary Methods For Measurement Of Form Errors Of Spherical Machine Parts, Proceedings of the 28th DAAAM International Symposium, pp.1101-1107, B. Katalinic (Ed.), Published by DAAAM International, ISBN 978-3-902734-11-2, ISSN 1726-9679, Vienna, Austria DOI: 10.2507/28th.daaam.proceedings.153

[4] Palenčár, R.: (2001) Uncertainties in Measurement I: Expressing Uncertainty, Automa, page 50

[5] Guide to the Expression of Uncertainty in Measurement (Směrnice pro vyjadřování nejistoty při měření). BIPM, IEC, IFCC, ISO, IUPAC,IUPAP, OIML, 1993

[6] https://ilac.org/ilac-mra-and-signatories/ (online). (cit. 2019-09-09)

[7] Broum, T; Dvorak, J \& Kleinova, J. (2011). Value optimization and risks elimination of product, Annals of DAAAM for 2011 \& Proceedings of the 22nd International DAAAM Symposium, Volume 22, No. 1, ISSN 1726-9679 ISBN 978-3-901509-83-4, Katalinic, B. (Ed.), pp. 757-758, Published by DAAAM International, Vienna, Austria, EU

[8] C\# Programming guide. https://docs.microsoft.com/en-us/dotnet/csharp/programming-guide/ (online)

[9] Marek, V. (2018). Sensitivity Analysis and Validation of a ThermoMechanical Model of a Spindle, Proceedings of the 29th DAAAM International Symposium, pp.0703-0708, B. Katalinic (Ed.), Published by DAAAM International, ISBN 978-3-902734-20-4, ISSN 1726-9679, Vienna, Austria DOI: 10.2507/29th.daaam.proceedings.101 